\title{
Opioids and Athletes: A Growing Problem and a Deadly Combination
}

\author{
Kimberly R. Outlaw, MSW, LCAS-A, CCSOTS ${ }^{1,2,3}$; Tracy Carpenter-Aeby, LCSW, PhD'; Victor G. Aeby, MS, EdD \\ 'East Carolina University, 20I Rivers, ECU, Greenville, NC 27858, USA \\ ${ }^{2}$ Licensed Clinical Addictions Specialist Associate \\ ${ }^{3}$ Clinical Certified Sex Offender Treatment Specialist

\section{"Corresponding author} \\ Tracy Carpenter-Aeby, LCSW, PhD \\ Professor, 220 Rivers, School of Social Work, College of Health \& Human Performance, East Carolina University, Greenville, NC 27858, USA; \\ E-mail: carpenteraebyt@ecu.edu
}

\section{Article information}

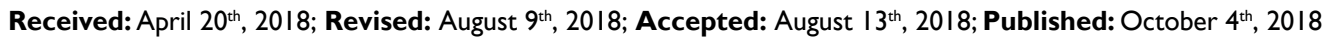

\section{Cite this article}

Outlaw K, Carpenter-Aeby T,Aeby VG. Opioids and athletes:A growing problem and a deadly combination. Sport Exerc Med Open J. 20I8; 4(3): 63-65. doi: I0.17|40/SEMOJ-4-I63

$\mathrm{T}$ he use and abuse of opioids has become a public health issue in the United States and is identified as especially problematic among populations that are prone to high levels of pain like cancer patients and those who have undergone surgery as well as those who more frequently experience injuries and are prescribed narcotic pain relievers, such as athletes. ${ }^{1}$ In fact, while existing research tends to support that participation in sports works for many young athletes to keep them away from drugs, the inherent risk of injury that is associated with sports makes them more vulnerable than their non-athletic peers to being prescribed an opioid pain medication during their athletic career. ${ }^{2}$ In an earlier study by Veliz, et al the researchers established that young people who participated in youth sports during high school were more likely than those who did not to experience a lifetime problem of medical prescription opioid use as well as diversion of opiate medications to others. This is critical information when considering that as much as $20 \%$ of student athletes sustained injuries during interscholastic sports events with just short of $50 \%$ of those injured requiring surgery and the consequent prescription of opioid pain relievers. ${ }^{2}$ Even more, it supports the notion of athletes who typically pride themselves in pursuing proper training and leading healthy lifestyles ultimately using heroin and other opioid drugs only to "find themselves mired in a life of street drugs and crime."

While the issue of opioid use among athletes is addressed primarily in the research that focuses on the use of opioid drugs among young athletes, there is some research that points to their use among athletes in professional sports. Unfortunately, there is a general lack of statistical evidence published on the use of drugs by athletes, which may be attributed to the fact that athletes are typically less likely than non-athletes to report opioid abuse as well as the fact that opioids do not improve athletic performance and therefore cannot be explained away by anything more than a clear addiction. ${ }^{3}$ What statistics do exist show that as much as $71 \%$ of former National Football League players interviewed by researcher reported that they were involved in the non-medical use of prescription opioid drugs during their careers, many of which were initiated into opioid drug use following sports-related injuries. ${ }^{4}$ The research by Ford et al. ${ }^{4}$ found that athletes, injured athletes, male athletes and injured male athletes were at greater risk for the use of opioid drugs. An especially compelling aspect of the use of opioids by athletes is that, unlike steroid or stimulant use, the use of opioids does not improve athletic performance and, in many cases undermines performance. Findings like these point to the fact that even athletes, who depend on the quality of their performance in their respective sporting events are vulnerable to the addictive attributes of opioid drugs like codeine, oxycontin, vicodin and even heroin.

The research demonstrates that the primary reason that athletes are vulnerable to opioid addiction is not because it improves their athletic performance. On the contrary, while opioid drugs can initially elicit the feelings of "euphoria and overall wellbeing," they work to reduce athletic performance because they cause the user to feel tired, sedated and confused as well as cause their respirations to decrease, none of which supports athletic performance. ${ }^{5}$ Opioids can also have a devastating effect on athletic performance because they can change heart, lung and bone func- 
tion. ${ }^{5}$ The abuse of opioid drugs by athletes to achieve the perceivably positive symptoms of euphoria and sense of wellbeing can manifest in the use of IV drugs, oral drugs or both depending largely on how they were introduced to the drug, the type of drug that they have the greatest access to and issues like the ability to pay for such drugs. The research demonstrates that many athletes, including young athletes manage to extend their use of opioid drugs beyond their medical needs while some athletes start the use of opioid drugs in response to their use by peers who were initiated by a medical need. What is critical is that the friends and families of those athletes that find themselves addicted to opioids learn to identify the signs and symptoms of the addiction and support them in receiving the appropriate treatment for their addiction. Unfortunately, as much as the opioid epidemic throughout American society has reached epidemic proportions there is still an identifiable lack of information from sports-related substance abuse sources, including official sports organizations, on the signs of opioid abuse, with many focusing only on the symptoms of alcohol, stimulant and marijuana use and abuse. ${ }^{6}$ Nevertheless, the general lack of statistics or other information on the use of opioids by athletes may be attributed to the fact that the proportion of opioid users in the United States who are athletes is relatively small however, the size of this population should not be the deciding factor on how much attention is paid and resources allocated to reducing and preventing their addiction. ${ }^{2}$

The opioid crisis has reached crisis proportions in America, touching every demographic and increasing in urgency as more Americans succumb to this addiction. The roots of this sinister epidemic started in the wide distribution of pain medications meant to help with acute and chronic pain. The result has been an opioid addiction that has resulted in people that would never otherwise consider using heroin to find themselves mired in a life of street drugs and crime. This is particularly true of athletes, who often suffer from chronic pain after pushing their bodies to the limit. When they are treated for pain with opioid medications, they may find themselves in a downward spiral that not only ruins their athletic prowess, but also leads to an addiction they cannot control. Doctors should refrain from widely prescribing pain medications for injuries that may not require the potency of opioids in an effort to avoid initiating and perpetuating cycles of addiction.

Athletes are accustomed to being in elite physical condition, and they may find that they are unable to pursue their goals if struggling with addition to opiates. Moreover, abuse and addiction can lead to other diseases and disorders (particularly if the drug is being injected intravenously) that would destroy any chance of continuing a career. The physical and physiological dependence on the opiates would become more important and all-consuming than their athletic careers. ${ }^{7}$ The bigger issue, however, is when the prescribed medication ends, the addiction remains. The downward spiral includes the high cost of illegal opiates. When illegal opiates are no longer an option, people (including athletes) with addictions have no other choice than to turn to the cheaper heroin. This is just as effective, but far less expensive. The descent into heroin addiction forces athletes to become shadows of their former selves and to become involved in the world of illegal drugs. Athletes that move from prescription opiate addiction to heroin enter a world outside of illicit prescriptions and popping pills. The move to heroin is even more dangerous, as heroin addicts often ingest the drug intravenously (sometimes even sharing needles in the process) and the recent use of substances like fentanyl and carfantanyl have created a greater likelihood of overdose.

In addition to the physical and physiological implications of using narcotic medications recreationally and the dangers presented by their use, there is also a direct impact on the career of the athlete. ${ }^{8}$ Athletes are often subject to frequent drug testing. It is a prerequisite to participating in their sport of choice. Athletes that develop an opiate addiction may find that they fail drug tests, mitigating them from participating in their sport of choice. ${ }^{8}$ They may be eliminated, for life in some instances, for failing drug tests, particularly if they attempt to compete while under the influence. This is why athletes should not be provided with narcotics or any other medications/drugs that could be addictive or harmful to their health and impede their ability to compete.

The challenge of dealing with this issue is that athletes are sometimes subject to the advice of unscrupulous medical professionals that put competition over the health and wellbeing of the athletes. They often take pain medications without comprehending the risks for potential addiction or the impacts that these medications might have on their physical performance.

For these reasons, multi-disciplinary teams, such as rehabilitation counselors, social workers, and health educators, should be included in the decision-making along with coaches and physicians to determine the best paths for athletes. Understanding how people become addicted to drugs and the impacts that it has on their wellbeing and livelihoods is one area that in which knowledge and career planning for athletes can help them make informed decisions that may have life-long effects. There is already a burgeoning patient population in this area, perhaps, due to doctors making decisions in isolation. Interdisciplinary teams could help athletes make informed decisions that could possibly prevent significant increases if more athletes are given pain medication that could lead to addiction. This is especially true when athletes do not understand the consequences of taking these pain pills in the first place. Professional helpers, particularly addiction counselors, work with people struggling with addictions to reduce symptoms not increase them. However, some people such as athletes may need to feed the addictions rather than reduce the symptoms. As more athletes abuse prescription pain killers that they are prescribed, but do not necessarily need (specifically when there are non-opiate alternatives that are just as effective), the numbers of those addicted will continue to rise. There is life after sports but only if athletes are alive and well enough to experience it. 


\section{CONFLICTS OF INTEREST |}

The authors declare that they have no conflicts of interest.

\section{REFERENCES}

1. Centers for disease control and prevention (CDC). Addressing the prescription opioid crisis. Website: https://www.cdc.gov/rxawareness/pdf/Overview-Rx-Awareness-Resources.pdf. Accessed 2017.

2. Veli P, Epstein-Ngo Q, Austic E, Boyd C, McCabe SE. Opioid use among interscholastic sports participants: An exploratory study from a sample of college students. Res Q Exerc Sport. 2015; 86(2): 205-211. doi: 10.1080/02701367.2014.983219

3. Ford JA. Nonmedical prescription drug use among college students: A comparison between athletes and nonathletes. J Am Coll Health. 2008; 57(2): 211-219. doi: 10.3200/JACH.57.2.211-220
4. Ford JA, Pomykacz C, Veliz P, et al. Sports involvement, injury history, and non-medical use of prescription opioids among college students: An analysis with a national sample. Am J Addict. 2018; 27(1): 15-22. doi: 10.1111/ajad.12657

5. Exercise and opioids. Mayo clinic - consumer health. Website: https:/ /www.mayoclinic.org/healthy-lifestyle/consumer-health/ in-depth/opioids-and-exercise/art-20396866. Accessed 2018.

6. Hainline B, Bell L, Wilfert N. Mind, body and sport: Substance use and abuse. NCAA. Website: http://www.ncaa.org/sport-science-institute/mind-body-and-sport-substance-use-and-abuse. Accessed 2016.

7. Parrillo VN. Encyclopedia of Social Problems. California, USA: SAGE; 2008.

8. Reardon LC, Creado S. Drug abuse in athletes. Subst Abuse Rebabil. 2014; 5: 95-105. doi: 10.2147/SAR.S53784 